Report for 2.2.1 Task 3: Develop and Document an Advanced Human System Interface for the Generic Pressurized Water Reactor Simulator

September 2019

U.S. Department of Energy

Office of Nuclear Energy 


\section{DISCLAIMER}

This information was prepared as an account of work sponsored by an agency of the U.S. Government. Neither the U.S. Government nor any agency thereof, nor any of their employees, makes any warranty, expressed or implied, or assumes any legal liability or responsibility for the accuracy, completeness, or usefulness, of any information, apparatus, product, or process disclosed, or represents that its use would not infringe privately owned rights. References herein to any specific commercial product, process, or service by trade name, trade mark, manufacturer, or otherwise, does not necessarily constitute or imply its endorsement, recommendation, or favoring by the U.S. Government or any agency thereof. The views and opinions of authors expressed herein do not necessarily state or reflect those of the U.S. Government or any agency thereof. 


\title{
Report for 2.2.1 Task 3: Develop and Document an Advanced Human System Interface for the Generic Pressurized Water Reactor Simulator
}

\author{
Robert McDonald, Alf Ove Braseth \\ Jeffrey C. Joe, Project Manager
}

September 2019

Prepared for the U.S. Department of Energy Office of Nuclear Energy 



\begin{abstract}
This report describes the development of four new Operator Work Displays (OWDs). The work is performed for Idaho National Laboratory (INL) by Institute for Energy Technology (IFE). The OWDs are implemented, and initially tested at the Generic Pressurized Water Reactor (gPWR) simulator in HAlden Man Machine LABoratory (HAMMLAB), with the intent to install them on the gPWR in INL's Human System Simulation Laboratory (HSSL).

The OWDs are designed to bridge the gap between large overview displays and detailed operator workstation displays. The report presents their design rationale, which stem from human factors findings, industrial standards and guidelines and research into visual perception for computer displays.

The report presents initial experiences using the OWDs, and topics for further work.
\end{abstract}




\section{CONTENTS}

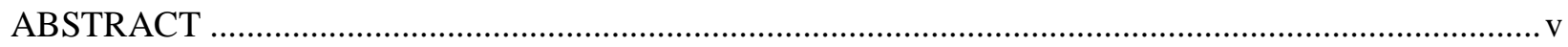

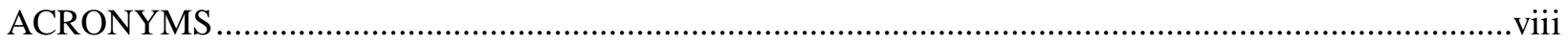

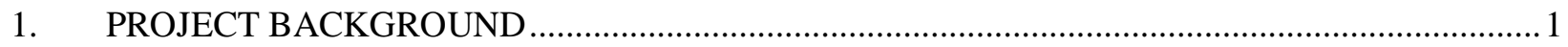

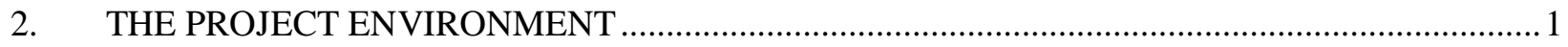

3. THE BASELINE - THE CURRENT HSSL DISPLAYS …............................................... 1

4. DESIGNING AND IMPLEMENTING THE NEW OPERATOR WORK DISPLAYS ................... 3

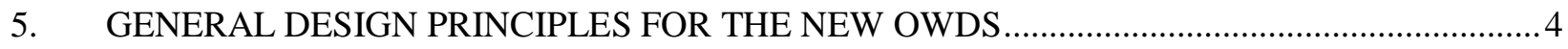

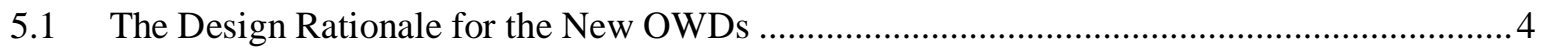

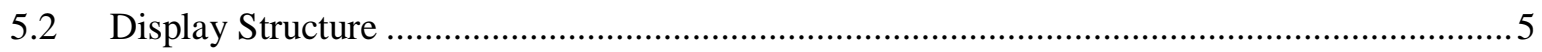

5.3 Graphical Layout - Visual Clutter and Data-Ink Ratio .....................................................5

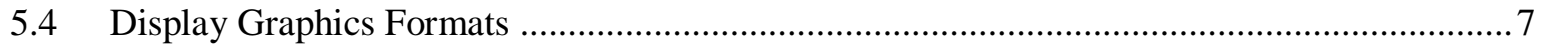

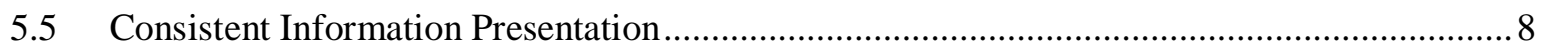

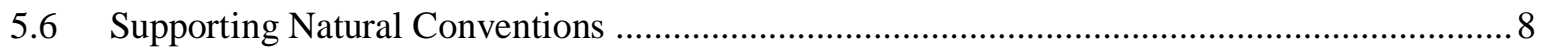

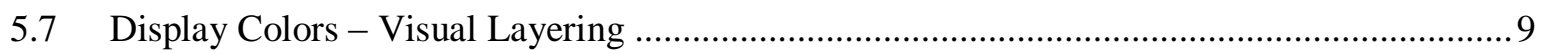

5.8 Display Colors - Foreground versus Background ........................................................... 10

5.9 Alarm Graphics - Special Considerations ................................................................... 10

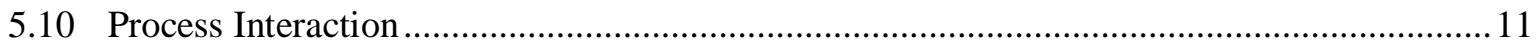

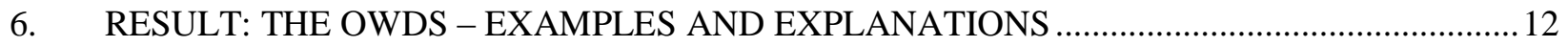

6.1 The Four New OWDS are Selected for Running Scenarios .............................................. 12

7. DISCUSSION: SHARED EXPERIENCES THROUGH THE ITERATIVE DESIGN

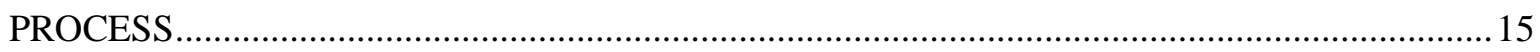

7.1 First Impressions Running the OWDS on the gPWR …................................................. 15

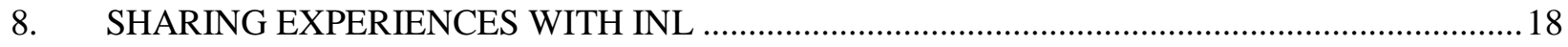

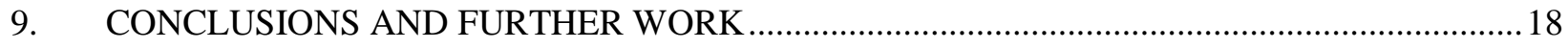

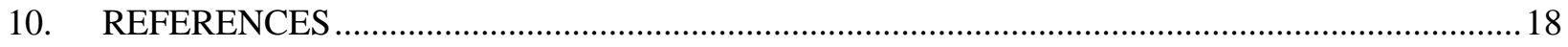




\section{FIGURES}

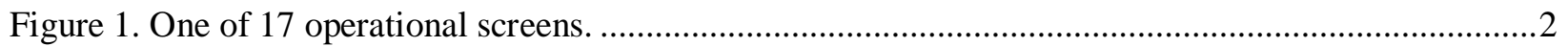

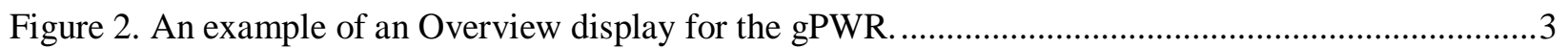

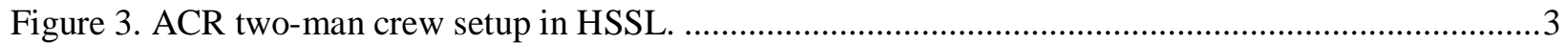

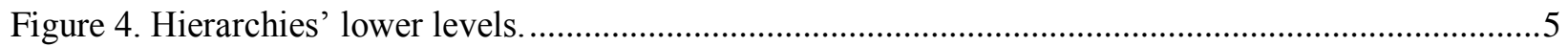

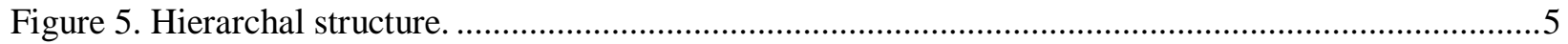

Figure 6. Graphical layouts showing less (left) and more (right) visual clutter. ......................................6

Figure 7. Graphical layouts showing less (left) and more (right) visual clutter that hides information........6

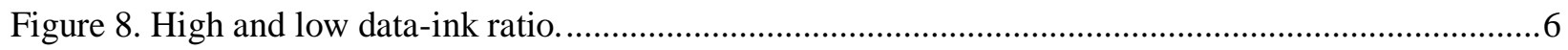

Figure 9. Typical display formats for control room displays. ..........................................................

Figure 10. Showing importance in visual consistency. .........................................................................

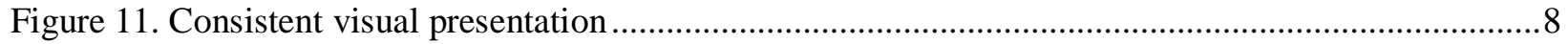

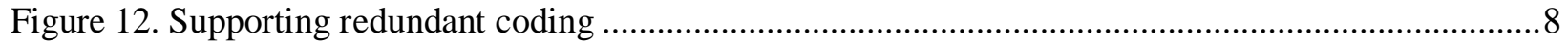

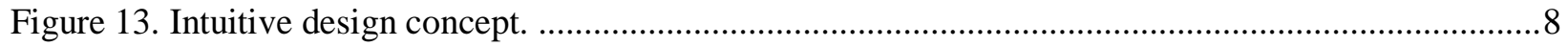

Figure 14. Gestalt principles, water at the bottom, gas at the top.........................................................

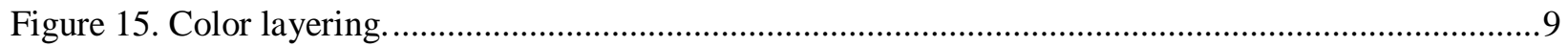

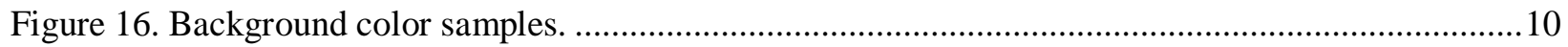

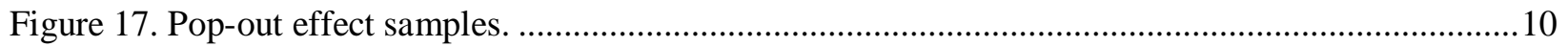

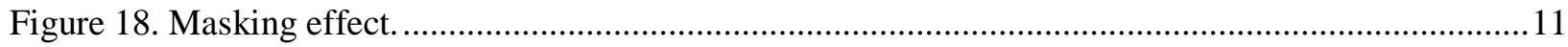

Figure 19. (Top) non-safety-oriented process action, (bottom) safety-oriented action............................12

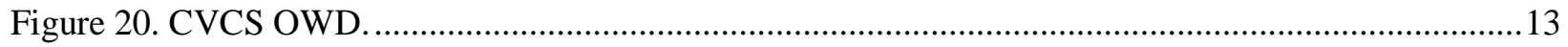

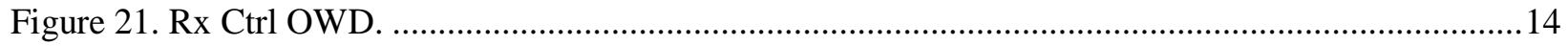

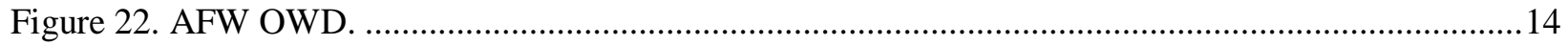

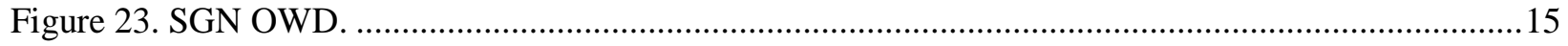

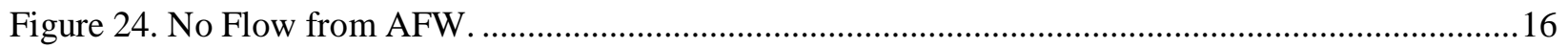

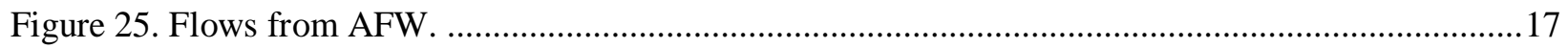

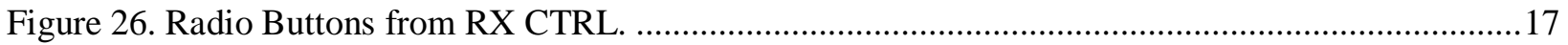




\section{ACRONYMS}

ACR Advanced Control Room

AFW Auxiliary Feed Water

BOP Balance of Plant Operator

CRS Control Room Supervisor

CVCS Charging and Volume Control System

ECCS Emergency Core Cooling System

EOP Emergency Operating Procedure

gPWR Generic Pressurized Water Reactor

HAMMLAB Halden Man Machine Laboratory

HSI Human System Interface

HSSL Human System Simulation Laboratory

LSD Large Screen Display

MCB Main Control Boards

MCR Main Control Room

OWD Operator Work Display

RO Reactor Operator

RX CTRL Reactor Control

SGN Steam Generator 


\title{
Report For 2.2.1 Task 3: Develop and Document an Advanced Human System Interface for the Generic Pressurized Water Reactor Simulator
}

\author{
1. PROJECT BACKGROUND
}

Idaho National Laboratory (INL) has contracted Institute for Energy Technology (IFE) to support the development of new human-factored operating displays for the generic Pressurized Water Reactor (gPWR) in the Human System Simulation Laboratory (HSSL) located at INL. The purpose is to improve on the displays that are currently being used in the Advanced Control Room (ACR) design of the gPWR in the HSSL. The initial HSI displays were created to maintain a similar look to legacy control rooms, with the exception that the systems were mouse controlled and it contained improvements in metering displays and system controls. The next step in developing a more modern control environment for the HSSL and the gPWR is to take the current ACR system, review the displays and then create better human-factored displays that provide more intuitive controls, indications, and system interaction for the operators.

\section{THE PROJECT ENVIRONMENT}

This project is performed at Institutt for Energiteknikk (IFE), which operates the OECD Halden Reactor Project (HRP). The organization has extensive experience from more than 20 years of research in Human System Interface (HSI) design and operation of nuclear power plant research simulators in the Halden Man-Machine Laboratory (HAMMLAB).

HAMMLAB is a suitable environment for developing the new display technology, as it serves two main purposes. The study of human behavior in interaction with complex process systems and the development, testing, and evaluation of prototype control centers and their individual systems. The goal of HAMMLAB is to extend the knowledge of human performance in complex process environments to adapt new technology to the needs of the human operator. By studying operator performance in HAMMLAB and integrating the knowledge gained into new designs, operational safety, reliability, efficiency, and productivity can be improved.

IFE is also using knowledge from several other projects into this current project, such as operational task-based displays, large-screen displays, innovative eye-tracking programs, and innovative performance testing methods. IFE also provides expert support in both nuclear power plant operations and setting up and running operations-based experiments and workshops.

\section{THE BASELINE - THE CURRENT HSSL DISPLAYS}

Currently, IFE's development of the ACR HSI was based on the current HAMMLAB model using the gPWR simulator. In HAMMLAB, all workstations allow the operators to control systems and components. Using this concept, the team developed a testing platform of three workstations for the Control Room Supervisor (CRS), Reactor Operator (RO), Balance of Plant (BOP) Operator, and the overview display. The system is flexible and is designed to be added to a system already comprised of workstations, glass-top bays to replicate the hard panel reactor trip switches, and Emergency Core Cooling System (ECCS), flow-loop indications, or other testing systems. The system is comprised of the operator workstations and the overview display.

The operator workstations have 17 operational screens from which the different systems and components are operated. These are divided into specific areas and systems designed to support operation of the plant. The RO has five specific screens designed to support them in maintaining focus on reactor power and controlling reactivity. The BOP Operator has an additional nine screens to support his or her 
needs to control the rest of the plant systems. The operators have three shared screens that they can both use in the conduct of their tasks. All screens can be accessed and operated by any of the three or four crew members; in the event of a workstation failure, plant operations can quickly and easily shift to a different workstation. Three information screens are for the crew: Alarm and Events, Safeguards, and Trends. The Alarm and Events screen provides information on alarms that are activated and allows the crew to acknowledge and reset the alarms from any control station. This screen also displays an event log to identify and store any action taken by the crew and automatic actions by the plant. This is stored so a review of events can take place for analysis and debriefing.

The Safeguards screen was developed by IFE to support the crew for a quick and accurate verification of any safeguards actuation. It also allows the crew to confirm all components previously identified as important to plant safety have been actuated and positioned as required. The Trend screen has 40 predesigned trends, but the operators can create additional trends. The trends can be adjusted for time, scale, and color.

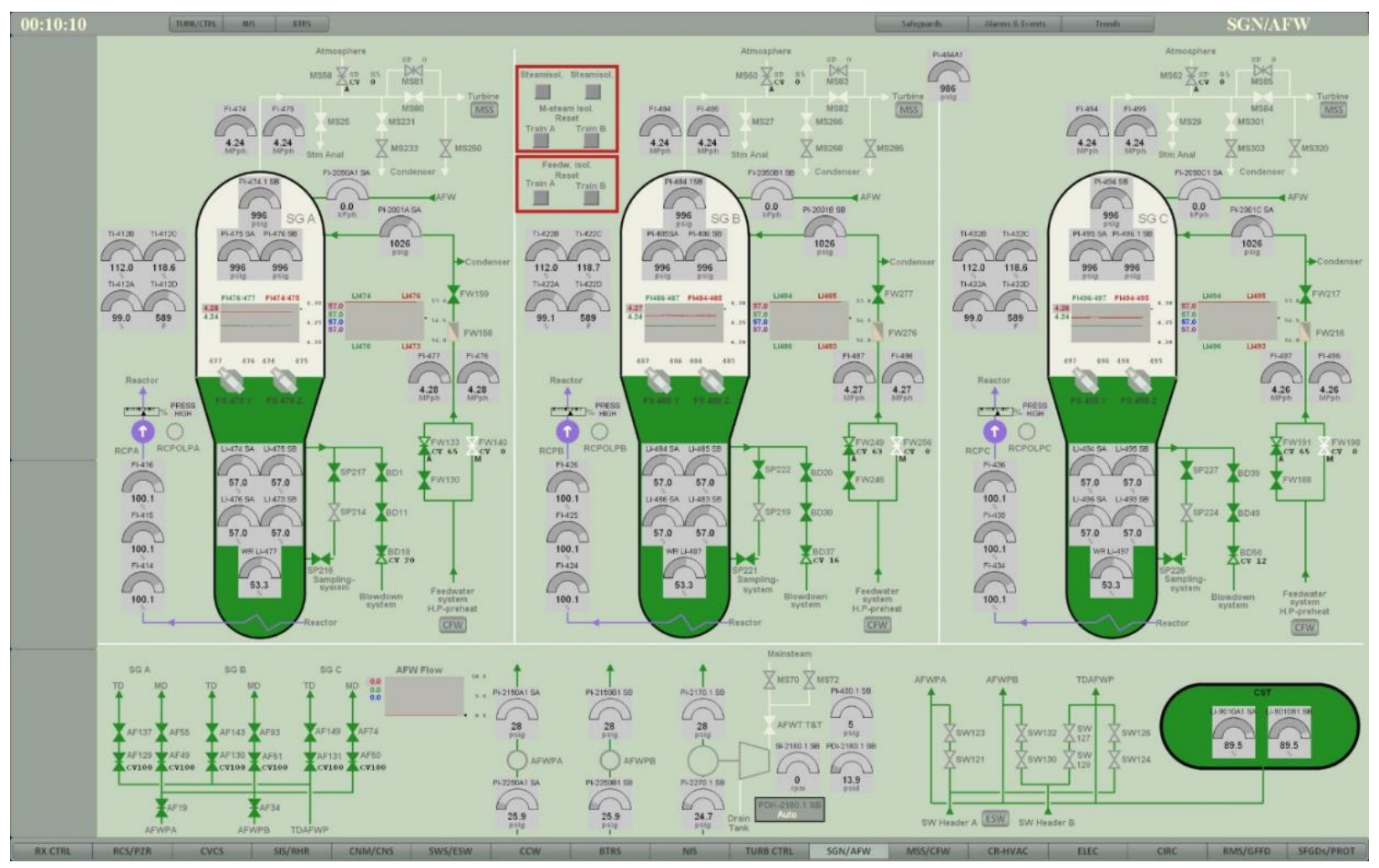

Figure 1. One of 17 operational screens.

The Overview display was developed using past experience in operator-based studies to identify the systems and components are normally monitored during emergency and normal operations. These displays use an integrated information concept developed and deployed in IFE's HAMMLAB. Various symbols and metrics provide the operator with a quick understanding and visual confirmation as to whether the plant system and its parameters are changing or stable. These displays use both visual and numerical cues.

In developing the Overview displays, the first iteration was initiated, by the developer/designer, who used previous design experience from similar task-based displays, adjusting for the new systems and components. By closely working with the operations expert and human factors support at IFE, a final Overview display was created and installed for testing in the HSSL. IFE also used plant-specific training material and staff with an operational background in pressurized water reactors, specifically 
Westinghouse four-loop designs. The Overview display provides the crew with the required information to answer the immediate action steps in the E-0, "Reactor Trip and Safety Injection," procedure after a reactor trip and determine if a safety injection has actuated or is required to be actuated. The Overview display is designed to support the crew throughout the Emergency Operating Procedures, as well as many of the Abnormal Operations procedures.

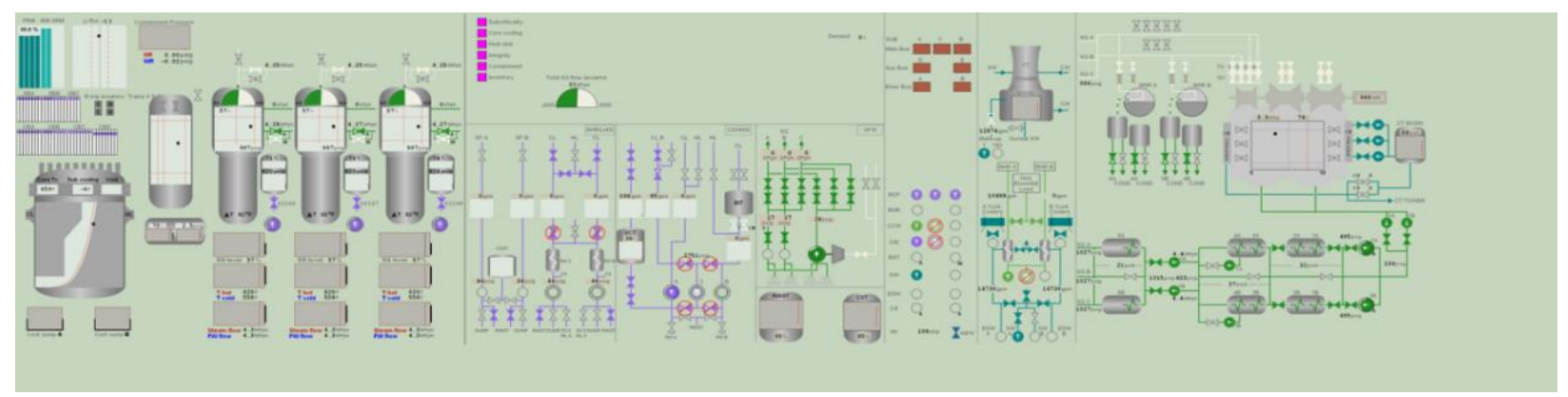

Figure 2. An example of an Overview display for the gPWR.

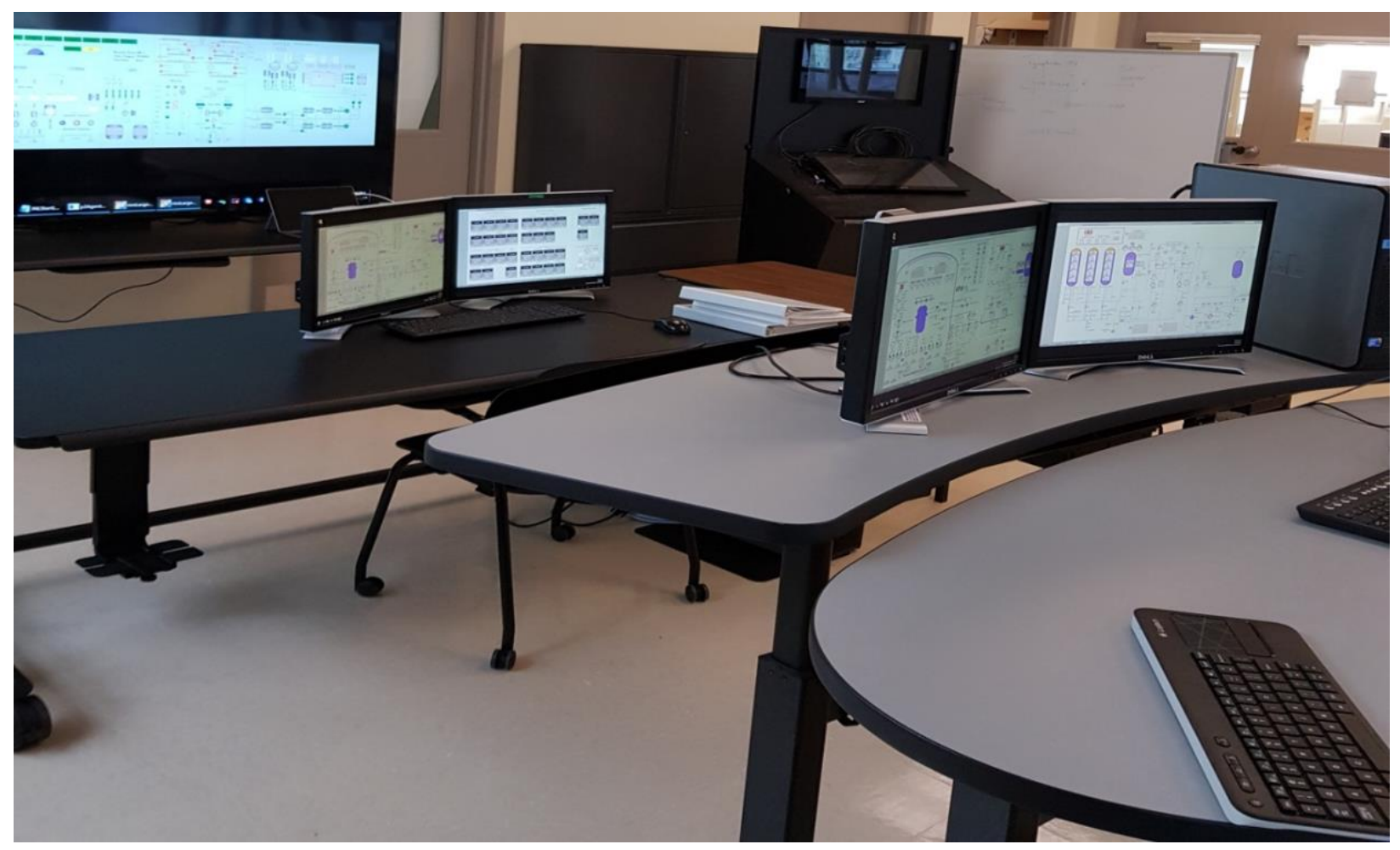

Figure 3. ACR two-man crew setup in HSSL.

\section{DESIGNING AND IMPLEMENTING THE NEW OPERATOR WORK DISPLAYS}

The new displays, called Operator Work Displays (OWD), are based on knowledge from human factors findings, industrial guidelines, and research into visual perception for computer displays. The OWDs are designed to provide an additional operating system for comparison studies along with the current operating system developed for the ACR in the HSSL. IFE decided to pick four of the current displays for review and the initial updating. This selection makes it possible to run different operational scenarios for further user studies. From this, the following systems were chosen: Charging and Volume 
Control System (CVCS); Reactor Controls (Rx Ctrl). Further, it was decided to split the original Steam Generator (SGN) Auxiliary Feed Water (AFW) display into two separate displays for better control and visual display of the AFW system.

The four displays were chosen based on their importance to the operators, both in day-to-day operation as well as emergency conditions. These four displays can be tested in both HAMMLAB and the HSSL, comparing them to the original designs. The four displays also contain the types of components, controls, and functions that are found in the other 17 original displays, then developing a solution for how components will look, or function will then be determined for all the other displays. From this, these four new OWDs will form the basis as the testing ground for the build out of future OWDs.

\section{GENERAL DESIGN PRINCIPLES FOR THE NEW OWDS}

This chapter describes first the general design-rationale for the new OWDs, then the design choices are thematically explained: display structure; graphics formats; display colors, alarm presentation and process interaction menus. Some of the sections are based on, or are reworked material from an internal report for the Nordic Nuclear Power plants and IFE: "IFE/HR/F - 2014/2016 "Human System Interfaces: Best Practices for the Nordic Nuclear Power Plants." The chapter is also influenced by the Ph.D. thesis of Braseth (2015). Please note that other background material is presented at the end of each section.

\subsection{The Design Rationale for the New OWDs}

The purpose of the OWDs is to bridge the "gap" between Large-Screen Overview displays or wall panels, and the detailed personal workstations. From this, the OWDs should be designed to provide operators:

- Rapid perception of a larger part of the nuclear process

- Easy access to detailed process displays (navigation) from the OWDs

- Perform general interaction with the process (change process values etc.).

To meet these objectives, the project suggests using a user/human-centered design approach (Endsley 2013 and ISO-9241-1 2000). Based on this, the project suggests to:

1. Start with operators' needs and capabilities, rather than to mold around technologies; however, the choice of technology should address the user experience.

2. Base the design upon an understanding of operators' tasks. Include a multidisciplinary design team in the design and development process.

3. Refine and drive design through a user-centered evaluation, using an iterative design process.

The first point is to be further explained in the following sections, how the design uses a scientific approach based on research into human factors, industrial standards and guidelines, and visual perception for computer displays. The display technology is based on a modern high-resolution 30-in. display, which is addressing a good user experience. This ensures satisfactorily reproduction of colors, lines, and text. The larger 30-in.-display surface is suitable to display larger parts of the process; hence, OWDs. However, the new OWD designs can be modified for other display types

The second point is covered by including expert operator knowledge into the design team in addition to an interaction designer. The third point of iterative design is done through a "lightweight" user-study evaluation early in the design process and more-detailed extensive studies later. The findings from these are to be fed-back into improved OWD design. 


\subsection{Display Structure}

Generally, the information space for nuclear plants is arranged in a display structure. Key process variables are often presented on the top layer, which might be a Large-Screen Display (LSD). Further details are presented in hierarchies' lower levels, and are illustrated in the Figure 4.

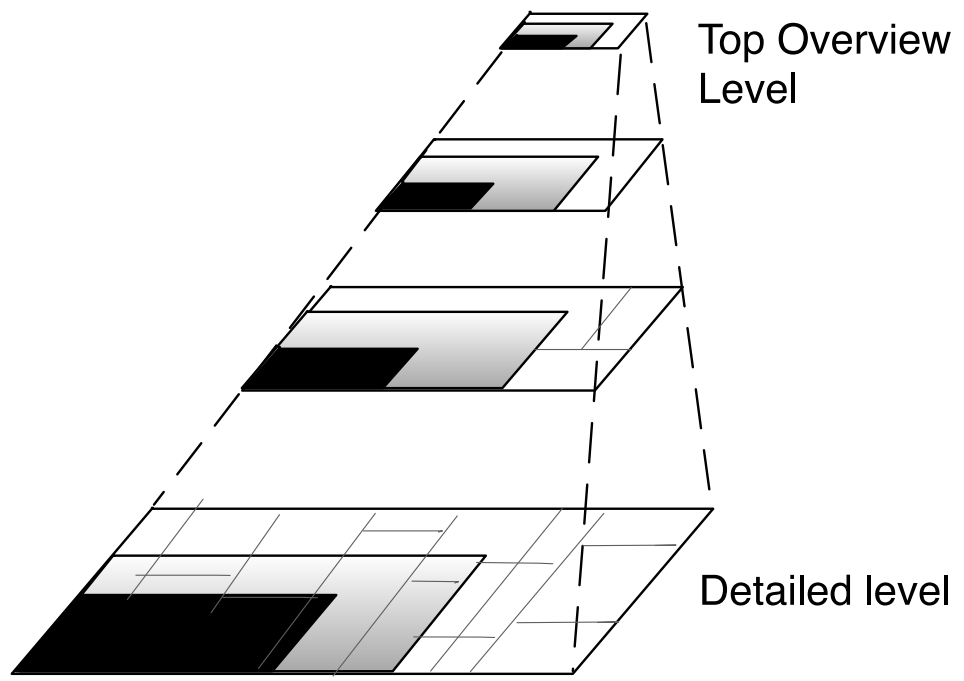

Figure 4. Hierarchies' lower levels.

The hierarchy is unfortunately affecting the operators' performance. In addition to time-consuming navigation, deep hierarchical structures put excessive load on visual memory. The problem is sometimes referred to as the keyhole effect. A very deep complex hierarchical structure should therefore be avoided; a simpler flatter hierarchy is preferable. The OWDs are designed to "bridge the gap" between the LSD and workstation displays; therefore, the OWDs offer direct navigation to other displays in hierarchical structure, this is visually explained in Error! Reference source not found..

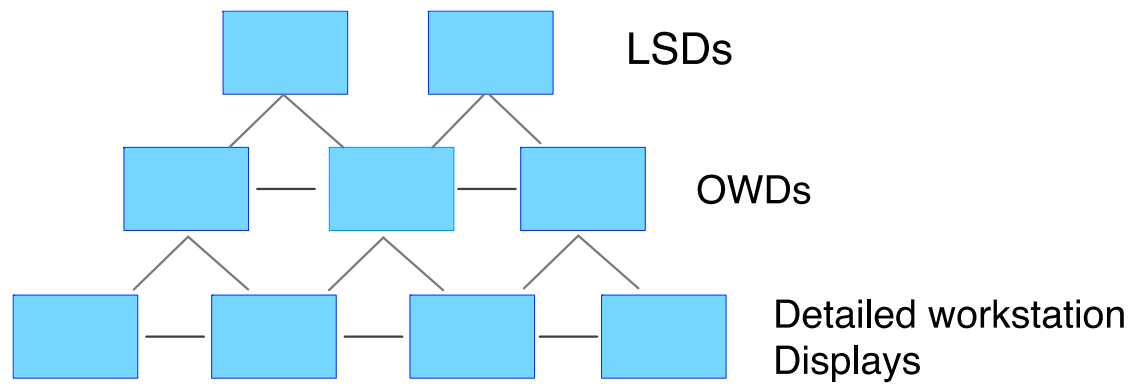

Background material: NUREG-0700, pp. 118-121; ASM Guidelines, pp. 74-75; Healey and Enns (2012); Ware (2008, p. 11); ISO-11064-5, pp. 7-9.

Figure 5. Hierarchal structure.

\subsection{Graphical Layout - Visual Clutter and Data-Ink Ratio}

The objective is to support a high level of readability through careful use of colors and layout, two concepts used on the OWDs are:

- Reduce visual clutter; focusing on information content.

- Support high data-ink ratio; increasing the dynamic information content, thus reducing the total number of displays (reduce need for navigation). 
By reducing visual clutter, the real information content can be highlighted. This in comparison to cluttered displays, where information can be hidden by context data such as thick lines, frames and overly bright colors. The following example visually explains how thick lines and bold fonts produce clutter; the OWDs use the left side figure:
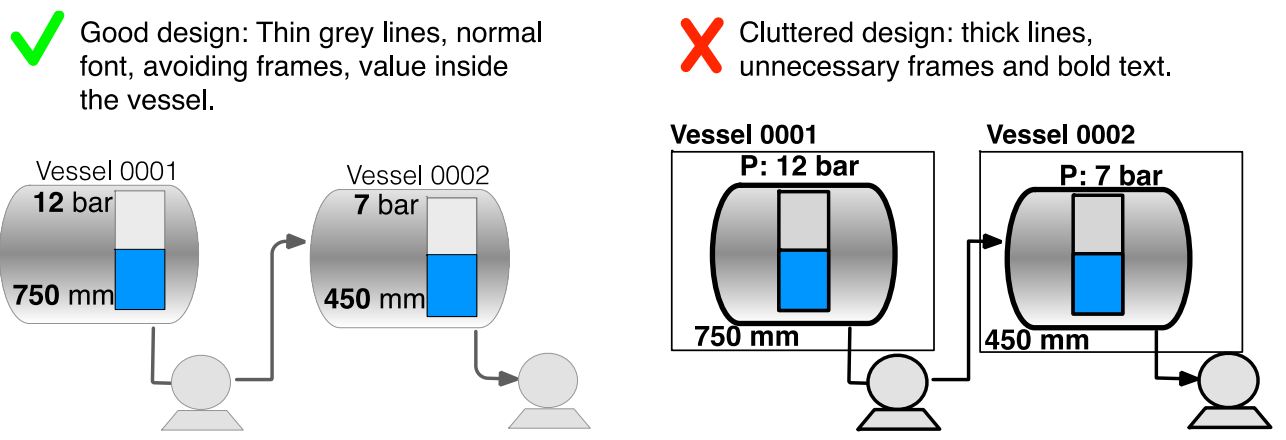

Figure 6. Graphical layouts showing less (left) and more (right) visual clutter.

Overly bright colors can create cluttered displays, and it can also mask or "hide" important process information. This is visualized in the following example; OWDs are designed as the left side of Figure 7.
Good design: careful use of colour and contrast, high and low level alarms are highlighted.

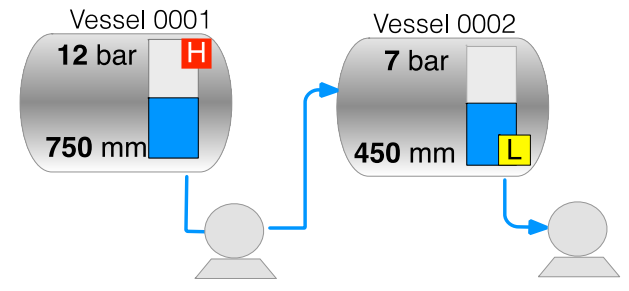

Cluttered design: colours are to rich and saturated. Alarms are masked.

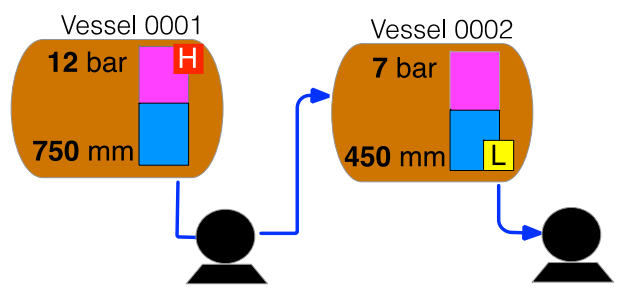

Figure 7. Graphical layouts showing less (left) and more (right) visual clutter that hides information.

Data-ink ratio can be described as (information content) divided/by (display area). As described in the previous section, navigation between displays is time consuming, and it leads to keyhole effects. A higher data-ink ratio reduces the number of displays, and a high data-ink ratio is therefore desirable for information graphics in general and for the OWDs. However, displays should have some open areas, which can prevent them from being too cluttered. The following example visually explains the concept of high and low data-ink ratio shown in Figure 8.

High data-ink ratio design

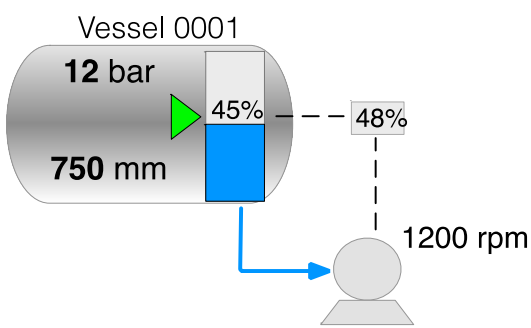

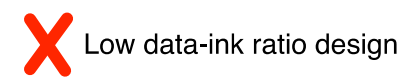

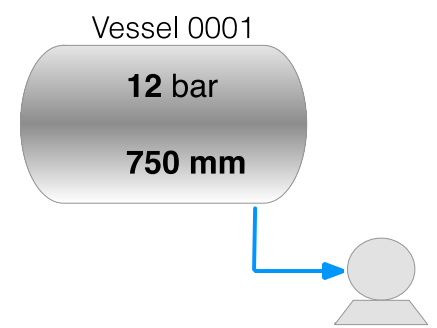

Background material: Clutter \& high data ink-ratio: Tufte (1990, 2001); NUREG-0700, pp. 31-32, 73-74; ISO 11064-5, pp. 1011; ASM Guidelines, p. 84, 87; ANSI/HFES 200, p. 375.

Figure 8. High and low data-ink ratio. 


\subsection{Display Graphics Formats}

Selecting the proper format for plant process information is important for rapid perception of the plant's state. The formats shown in Figure 9 are typically used for control room displays.

Text and numbers

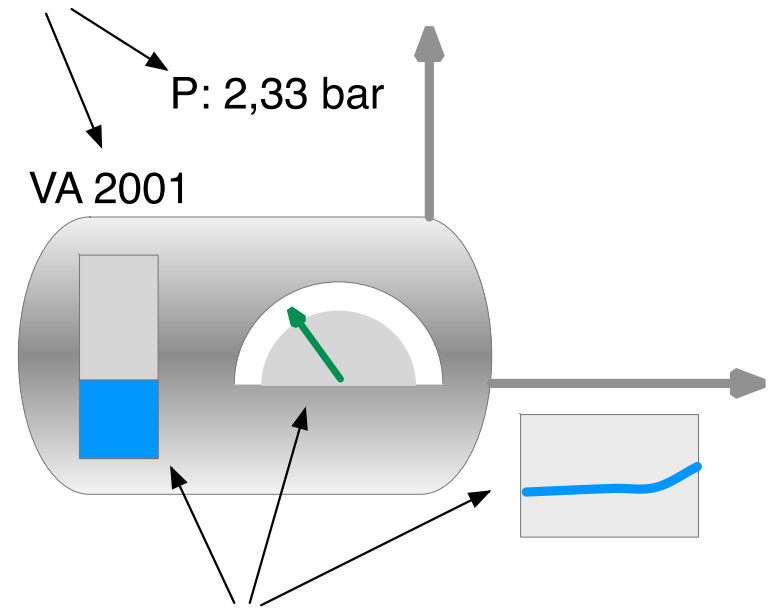

Analogue indicators

Figure 9. Typical display formats for control room displays.

Display design of the OWDs shall minimize the workload contribution to avoid information overload: from monitoring, operation, and problem solving. Analogue type indicators are in general well suited for such rapid perception and used for this purpose in the OWDs. Text and numbers are preferable for high accuracy readings.

The OWDs is designed to be consistent in the use of formats; this is visually explained in Figure 10.
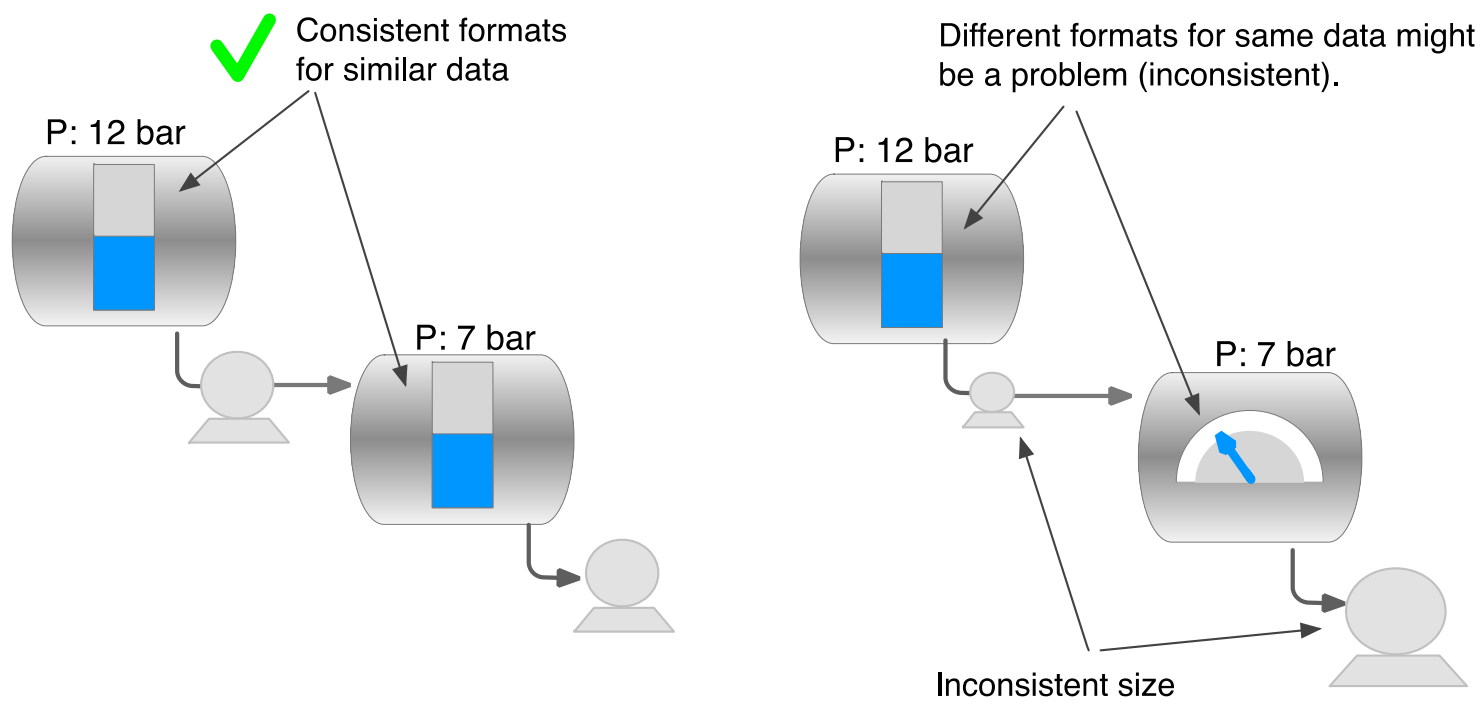

Background material: IEC 61772, pp. 11, 20, 21; NUREG-0700, p. 9.

Figure 10. Showing importance in visual consistency. 


\subsection{Consistent Information Presentation}

Consistency is not only about data formats, as described in the previous section, it is also related to the data format, the use of colors, and text. A high degree of consistency is a key to error free operation of the OWDs. This is particularly highlighted by Human Factors standards and guidelines. As an example, ordering of variables should be intuitive: A, B, C, and D. It is confusing if it is ordered: A, C, B and D, this is explained in Figure 11.

Use intuitive order
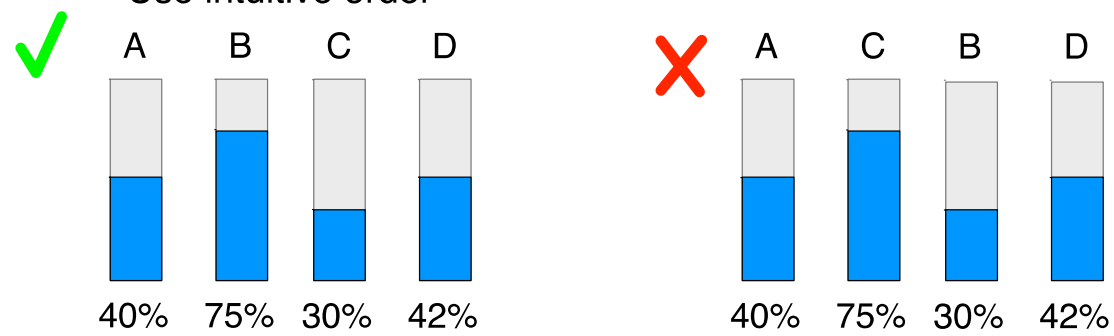

Figure 11. Consistent visual presentation

The same applies to the use of redundant coding, which can be preferable (see Figure 12). Redundant coding, unambiguous
design

$A$ in operation
$A$ is disabled
$A$ in operation
$A$ is disabled

Easily confused, what does

the signal mean?

\begin{tabular}{|l|}
\hline $\begin{array}{l}\text { Mode A operation } \\
\text { Out of operation }\end{array}$ \\
\hline $\begin{array}{l}\text { Mode A operation } \\
\text { Out of operation }\end{array}$ \\
\hline
\end{tabular}

Background material: NUREG-0700 part 1 pp. 10, 75; ISO 11064-5, pp. 10-11; ASM-Guidelines pp. 64, 87; ANSI/HFES 200, p. 375.

Figure 12. Supporting redundant coding

\subsection{Supporting Natural Conventions}

For intuitive perception of the OWDs, graphics should further support common expectations. This is important for designing graphics in line with operators' mental models. The operators' mental model should be followed for piping layout, fluid type, and alarm status. Figure 13 visually explains the concept of intuitive design as used in the OWDs:
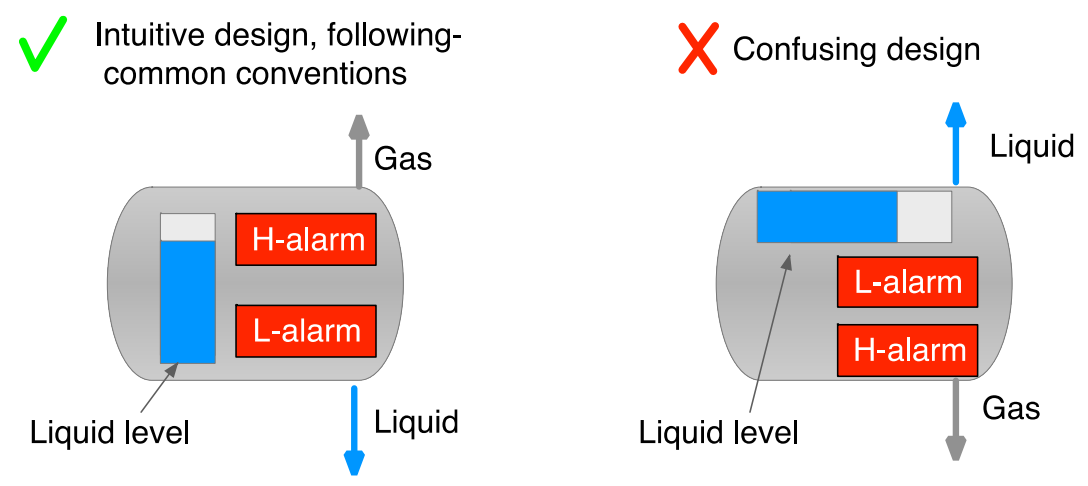

Figure 13. Intuitive design concept. 
For further to increase intuitiveness and readability, OWD information is grouped by proximity, similarity, and closure (Gestalt principles). These concepts are visually explained in Figure 14.

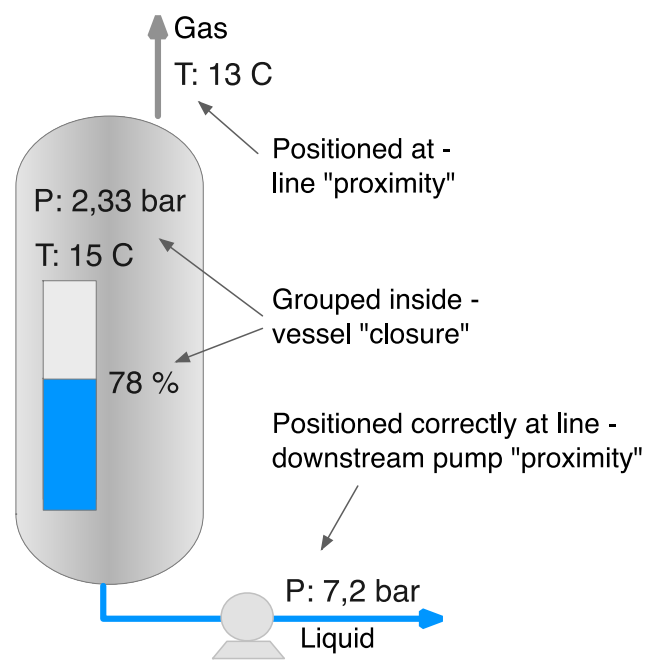

Background material: IEC 61772 p. 16; ISO 11064-5 pp. 7-9, 10-11; ANSI/HFES 200 pp. 377-379; Lakoff and Johnson (1999); Lidwell, Holden and Butler (2010).

Figure 14. Gestalt principles, water at the bottom, gas at the top

\subsection{Display Colors - Visual Layering}

Information layering can result in better information graphics. Correctly used, it creates a visual hierarchy making the most important information visually salient, while less important information is deemphasized. In a visually layered approach, the salience of graphical features should reflect the importance of the information, highlighting critical information.

Typically, the following layers are used in display design: background layer, static contextual layer, dynamic data layer, and highest priority signal data layer. The use of gray color layering with lower contrast is suitable for displaying the lower prioritized content, such as physical structures. Figure 15 visually explains how color layering is used in the OWDs.

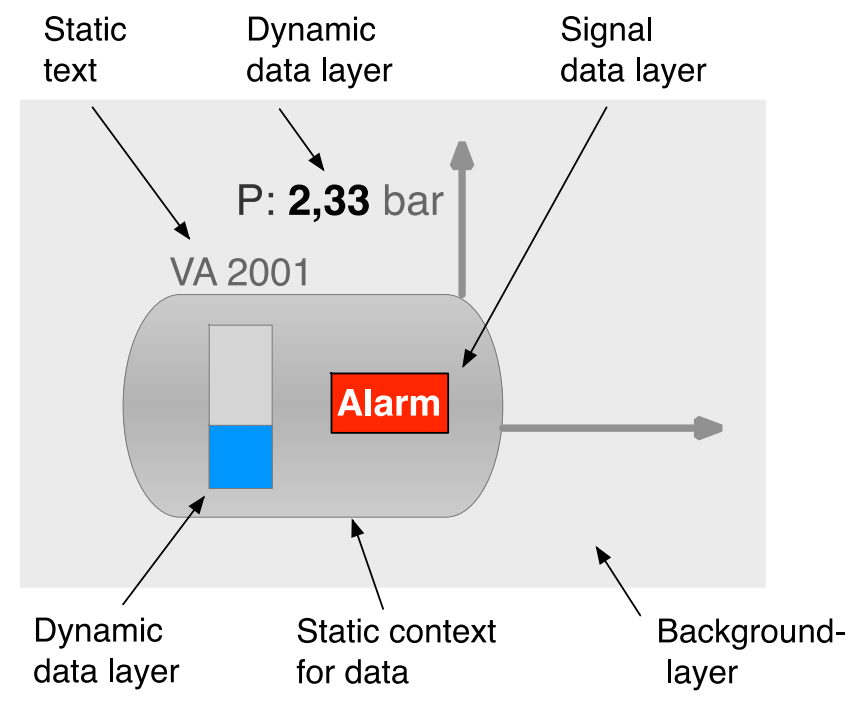

Background material: NUREG-0700 p. 15; ISO 11064-5, pp. 10-11, 25; ASM Guidelines, pp. 51-56; Tufte (2001, p. 174), Van Laar (2001), Van Laar and Deshe (2001).

Figure 15. Color layering. 


\subsection{Display Colors - Foreground versus Background}

To design for effective visual layering, the use of foreground and background colors in the OWDs are chosen carefully. Muted neutral backgrounds (flat light gray) is appropriate as a background color, this ensures good visual attention for foreground colors. A muted background color is also a good choice considering problems related to eyestrain, fatigue, and glare. The choice of background color can unfortunately mask foreground alarms and dynamic data. This is visually explained in Figure 16 (beige to the right masks the red and yellow alarms).

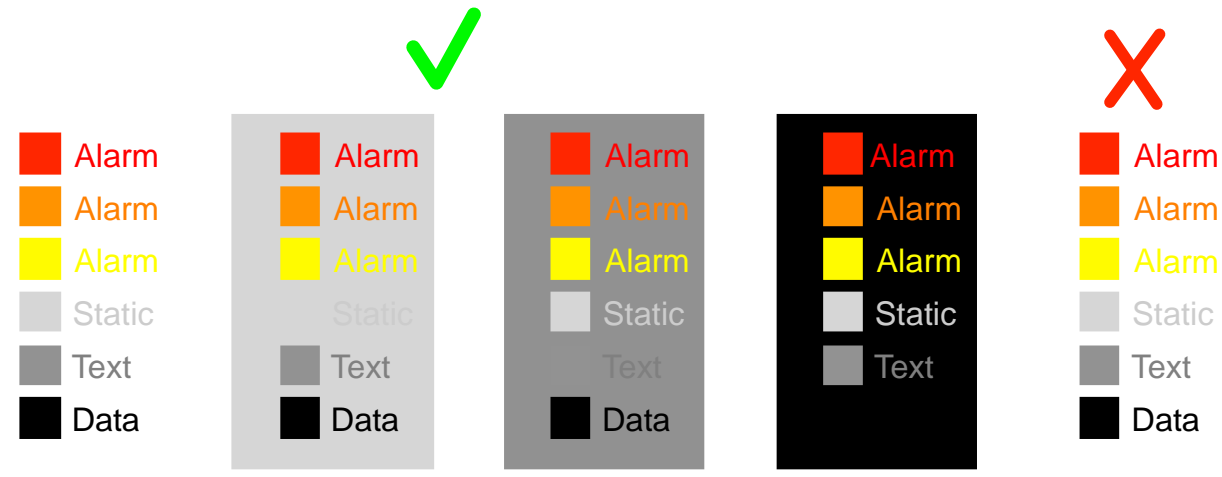

Background material: NUREG-0700 pp. 15, 60-63; IEC 61772 pp. 20-21; ISO 11064-5 pp. 10-11; ASM Consortium pp. 51-56, 96-99, 103-104; ANSI/HFES p. 408; Report f-12-1559 for HAMBO group; Bullemer et al. (2011).

Figure 16. Background color samples.

\subsection{Alarm Graphics - Special Considerations}

Alarm information is usually associated with signal colors such as red and yellow (visual top layer). The following section explains how to design for strong visual pop-out effects:

- By using color-filled alarm objects rather than alarm-frames.

- To avoid masking effects from visually "competing” elements.

It should be considered that filled elements give a stronger and more consistent visual pop-out effect than alarm frames; this is particularly noticeable for the use of yellow alarm color. It is advisable to use a thin black frame on yellow filled alarm objects for improved contrast; the concept as used for the OWDs is explained in the right side of Figure 17.

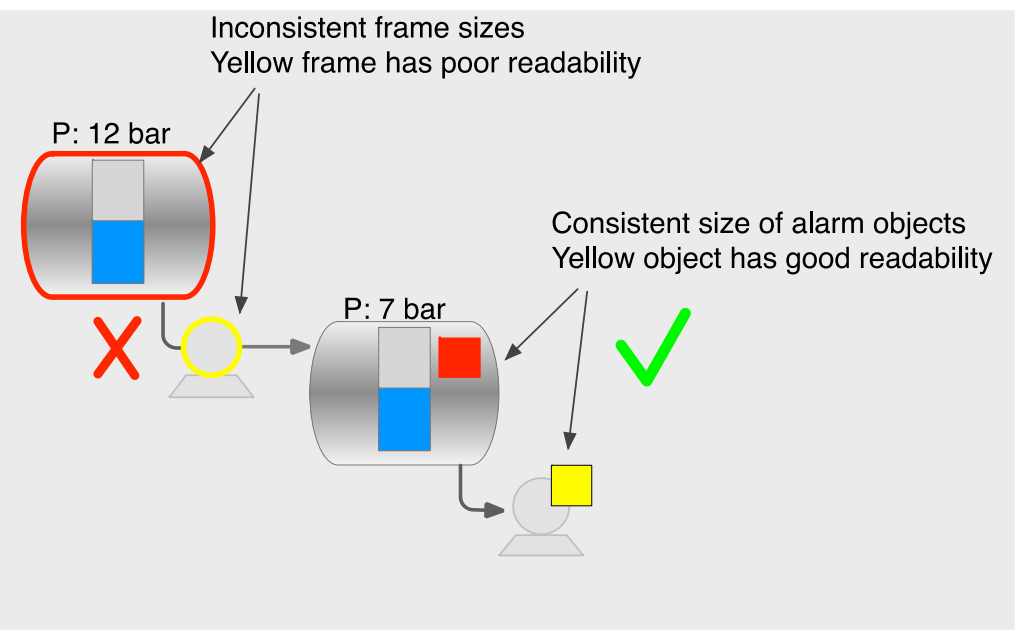

Figure 17. Pop-out effect samples. 
An unfortunate effect is "masking." This can be avoided by reserving colors and shapes to safety critical information. The masking effect by visually "competing red" elements is explained in Error! Reference source not found..
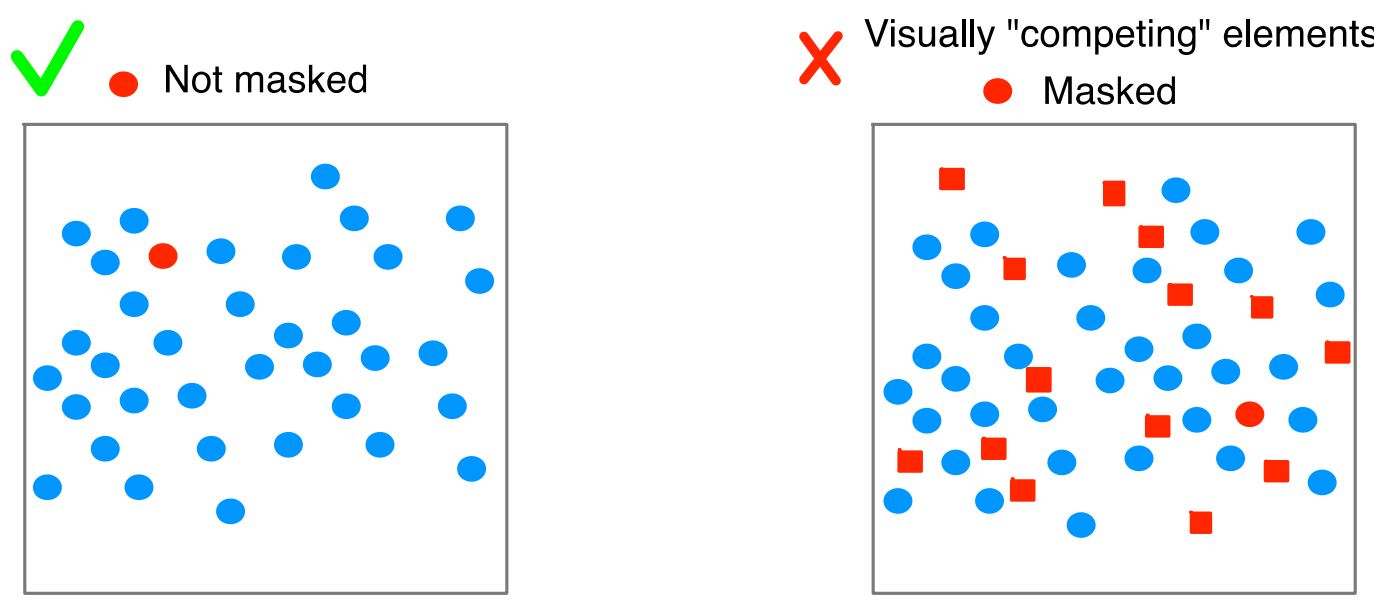

Background material: Ware (2008, 2013); Healey and Enns (2012).

Figure 18. Masking effect.

\subsection{Process Interaction}

The OWDs are offering the operators to interact with the nuclear process, such as opening valves, stopping pumps and changing other operational states. The goal of the OWDs is to offer interaction through:

- Efficient and intuitive menus

- A high degree of operational safety.

For the first point, to be efficient, the interactive menus are be placed in the display surface where their intended function is naturally mapped. Typically, the menu must be close to other related information objects. This will also strengthen the operator's mental model for how perform process changes, and to build a model of the expected outcome of the action.

Confirmation of actions can prevent slips, which are unintended actions. Therefore, the OWDs are using "confirmation" (a two-stage process) where the operational safety of actions is high. However, it is not used for less safety-oriented action, as it can be cumbersome and increases workload. The concept is visually explained in Figure 19 (top) where the first is a non-safety-oriented process action, the bottom figure is a safety-oriented action. 

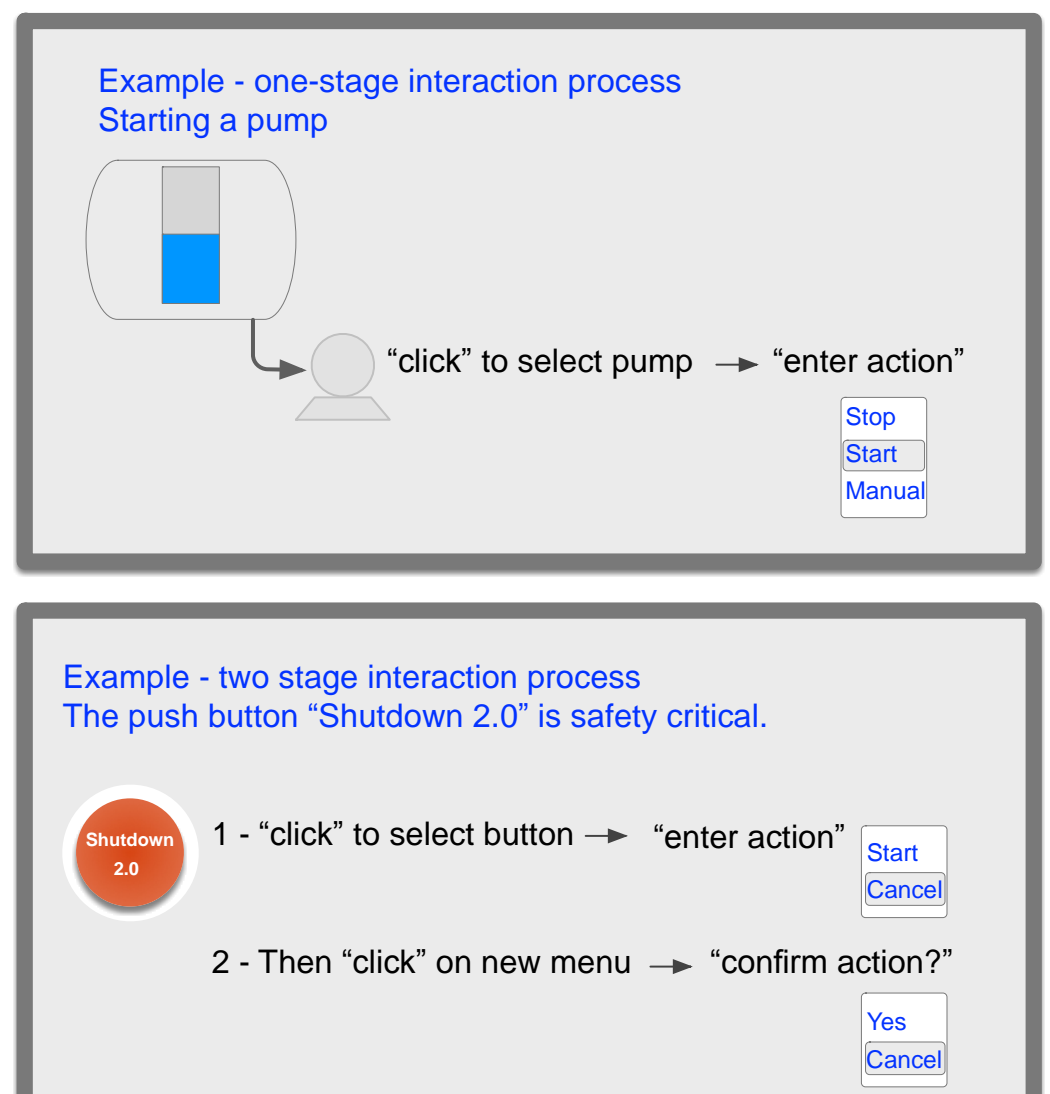

Background material: Lidwell, Holden and Butler (2010) pp. 22; 54; 152, 154.

Figure 19. (Top) non-safety-oriented process action, (bottom) safety-oriented action.

\section{RESULT: THE OWDS - EXAMPLES AND EXPLANATIONS}

This chapter explains the new OWDs through examples for each display. However, first is a rationale explaining the selection of which OWDs were to be designed in this first part of the project.

\subsection{The Four New OWDS are Selected for Running Scenarios}

The plan is to design OWDs for the greater part of the nuclear and secondary processes of the gPWR simulator. As a first step, thus a selection of four displays has been made. The main purpose of these is to demonstrate the concept of the new OWDs, which is to "bridge the gap" between Large Overview Displays and detailed personal workstation displays. Therefore, it is necessary to be able to perform user studies of the OWDs; in order to do that, relevant operational scenarios must be developed to the user-studies. Based on this, the following parts of the process are needed:

Suitable scenarios for testing OWDs that require the use of the five most commonly used Emergency Operating Procedures (EOPs) are:

- E-0 Reactor Trip Response

- E-1 Loss of Reactor or Secondary Coolant

- E-2 Faulted Steam Generator Isolation

- E-3 Steam Generator Tube Rupture

- ES-0.1 Reactor Trip Response. 
The scenarios are created to have the operators enter the EOPs and test the effectiveness of the OWDs in identifying the initial failures; diagnosis of the condition of the reactor and any failures as well as being able to quantify if the conditions are worsening or stable. The ideal OWDs would support the operators once they have entered the EOPs, in their diagnosis and support, their decisions on the proper transitions within the EOP network. An additional condition the OWDs should support would be the restoration of the plant once the right conditions are met in the EOPs. Some examples would be resetting safety signals and cooling down the Reactor Coolant System (RCS).

From this, the following four OWDs were created to test the concept of the human-centered design and use during testing of scenarios in the EOP network (see Figures 20-23).

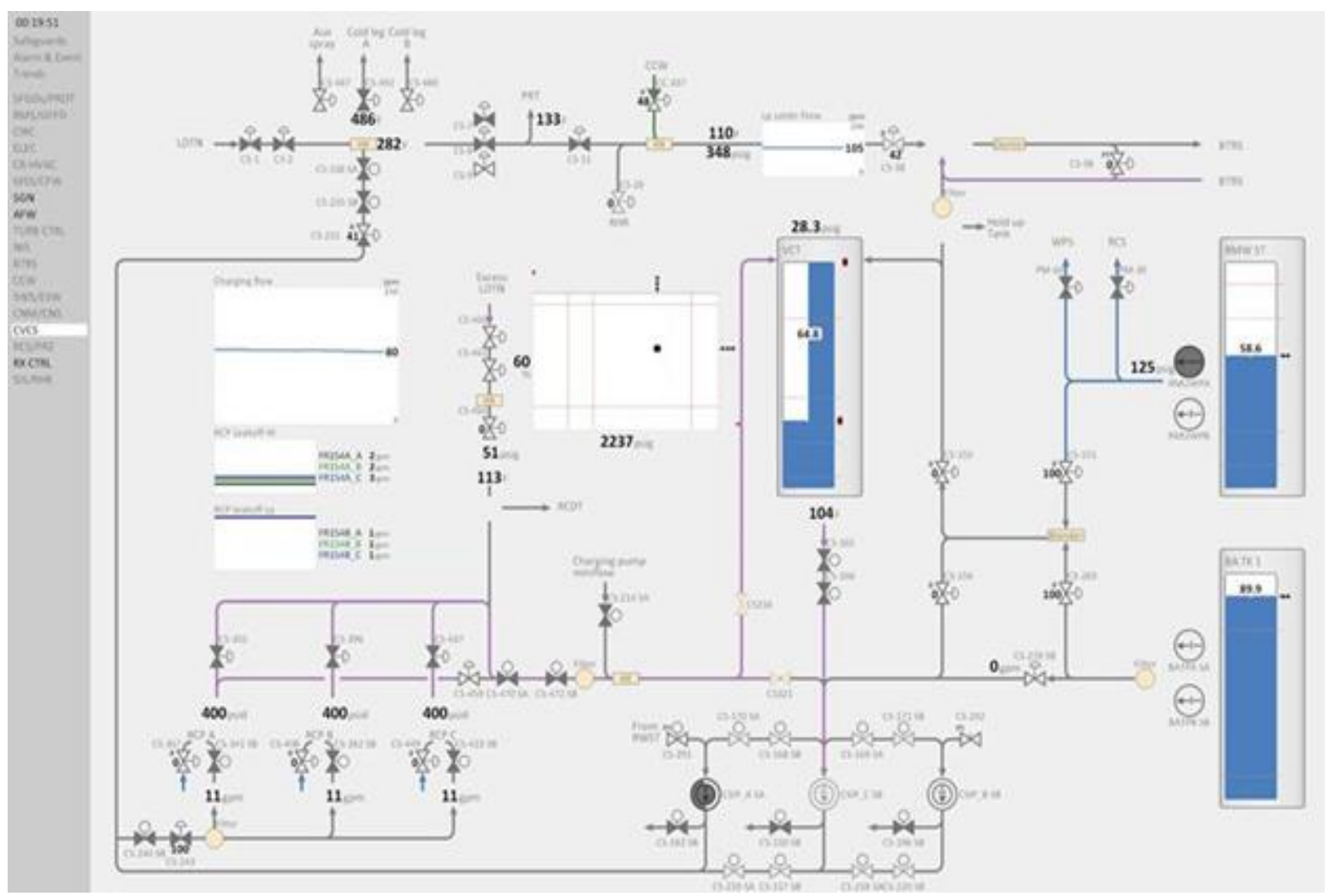

Figure 20. CVCS OWD. 


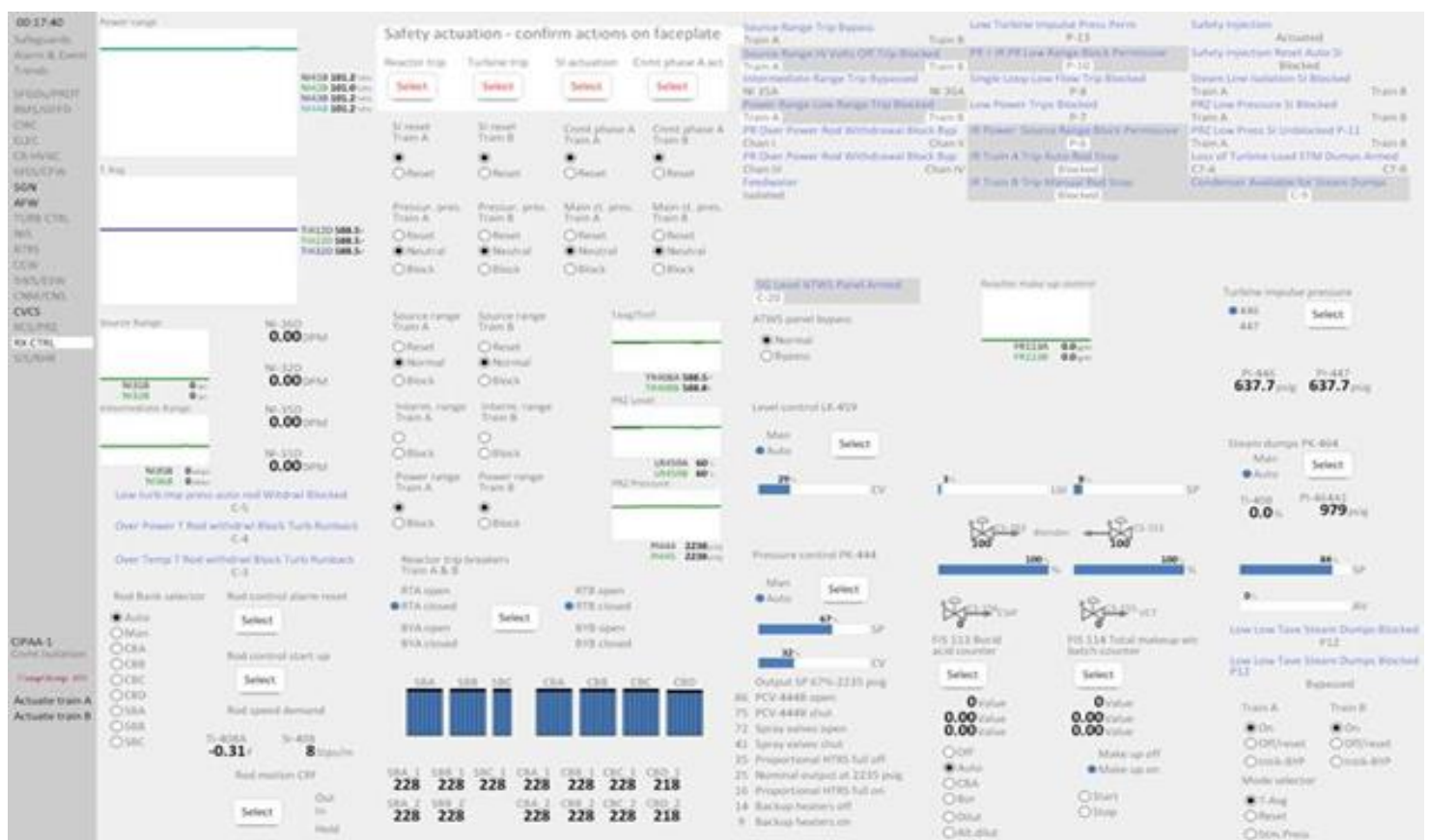

Figure 21. Rx Ctrl OWD.

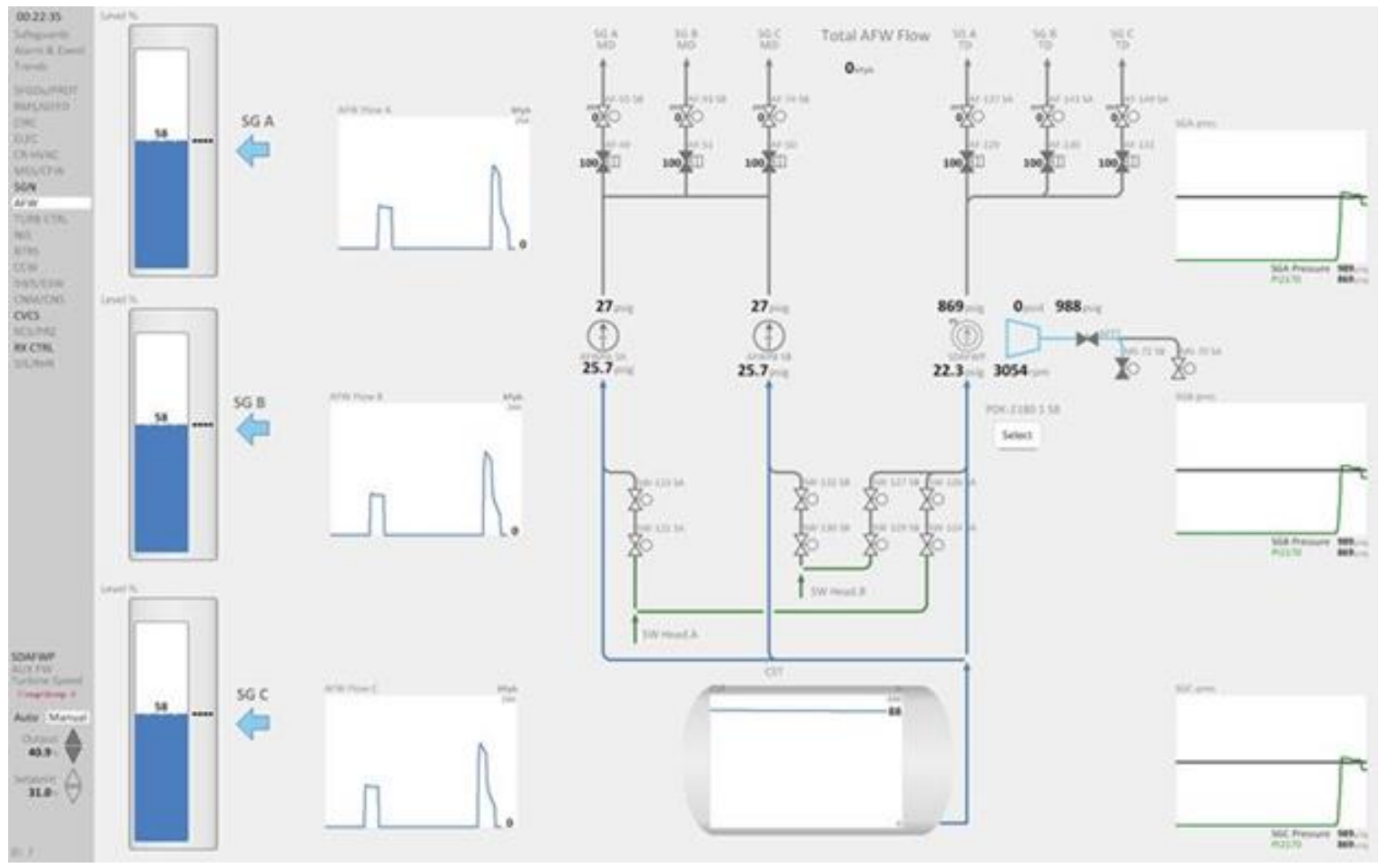

Figure 22. AFW OWD. 


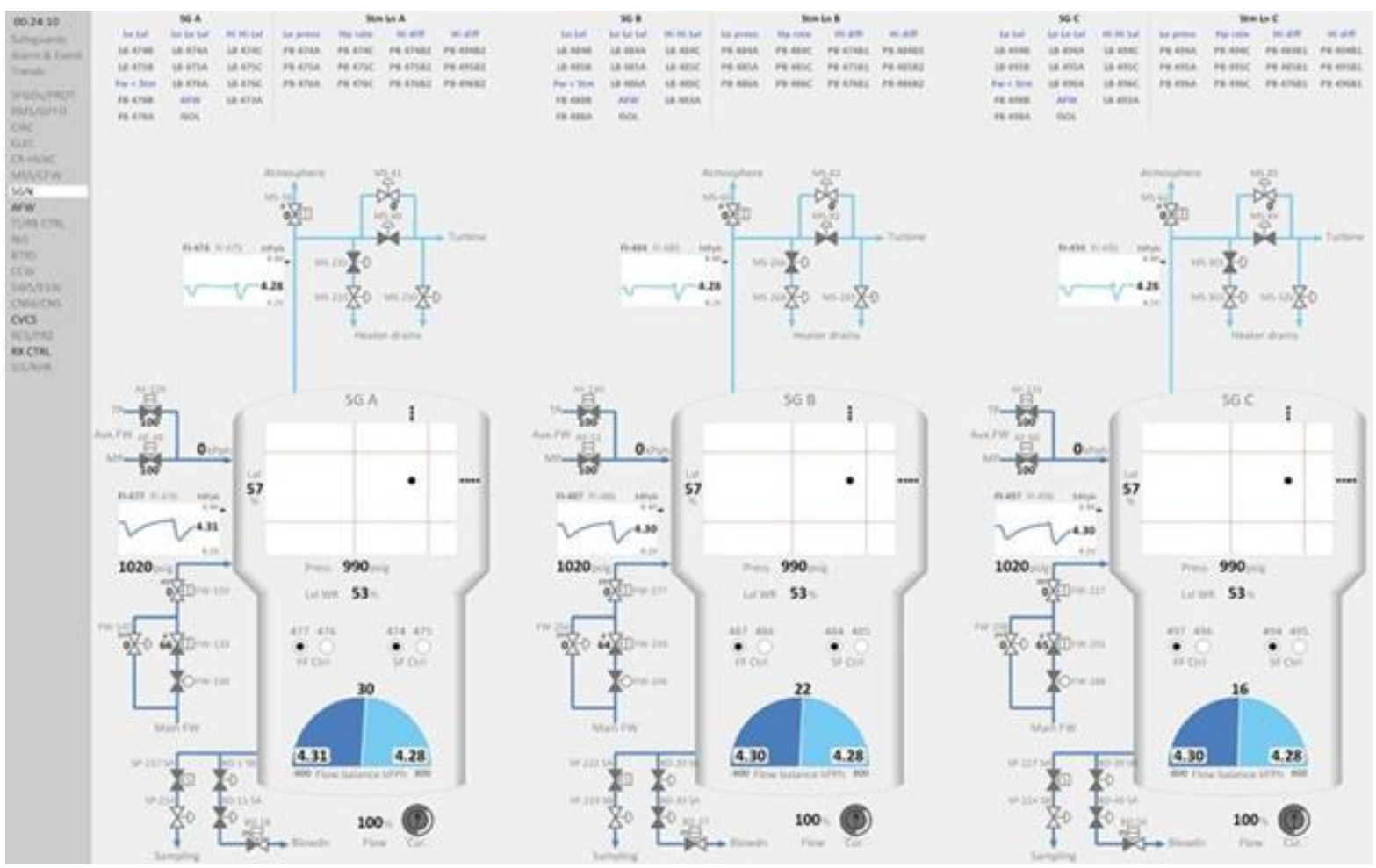

Figure 23. SGN OWD.

\section{DISCUSSION: SHARED EXPERIENCES THROUGH THE ITERATIVE DESIGN PROCESS}

This section explains how the new OWDs, which are information dense and great complexity, are improved through an iterative process. The chapter shares our experiences so far working with these new displays.

\subsection{First Impressions Running the OWDS on the gPWR}

IFE's development of the OWDs was continuously tested in HAMMLAB using the gPWR simulator. A side-by-side comparison between the old HSI displays and the OWDs was performed to verify all major components and systems were maintained. Verification was made that there was no loss of functionality of components or controllers between the two displays. We verified the concept of flow/no flow on both the AFW and the CVCS displays. We then ran a series of scenarios to test the ability to control systems and component under both emergency conditions and abnormal conditions. We further focused on the EOPs to ensure that we could meet the required times of operator actions, as well as all the necessary controls required to support the EOPs.

During the initial testing, we did discover problems with some systems control as well as some new additional features we wanted to add to the displays. An example of this was to add a total AFW flow indication to the AFW display. This is something that is called out frequently in the procedures, and currently requires the operator to calculate six different flow indications. The display now provides that calculation on the screen at the discharge of all three pumps (see Figure 9). We initially found some problems with the flow/no flow design, specifically how will we treat conditions where the flow splits and can go in two or three directions? We solved this problem by making the determination that if flow is possible or the piping is pressurized up to the point of the next closed valve, the indication will show as flow up to that point but no flow after the closed valves or stopped pump (see Error! Reference source 
not found.). This approach provides a consistent view of the system process providing positive feedback to the operator on the status of the system once flow has started by either opening a valve or starting a pump (see Figure 9).

An additional problem was discovered under testing of what is the best way to present reset or reset/block push buttons or switches. When moving to a fully digital system there is a loss of the tactile sense or feedback to the operator. Many of these types of buttons/switches are found on the Rx Ctrl display. The solution for this was to use a type of radio button where the operator clicks on the respective block/reset and the radio button will change to provide a positive visual feedback (see Error! Reference source not found.). A final test for these four displays will be conducted the week of September 24, 2019, with an Operations crew from a U.S. nuclear power plant.

We will run a couple of predetermined scenarios to see how the operators use the OWDs and then collect their feedback. The test will be conducted at the end of the week after the crew have been trained and used the original displays and several scenarios. This will allow for a good comparison between the two types of displays and a good chance to find additional enhancements.

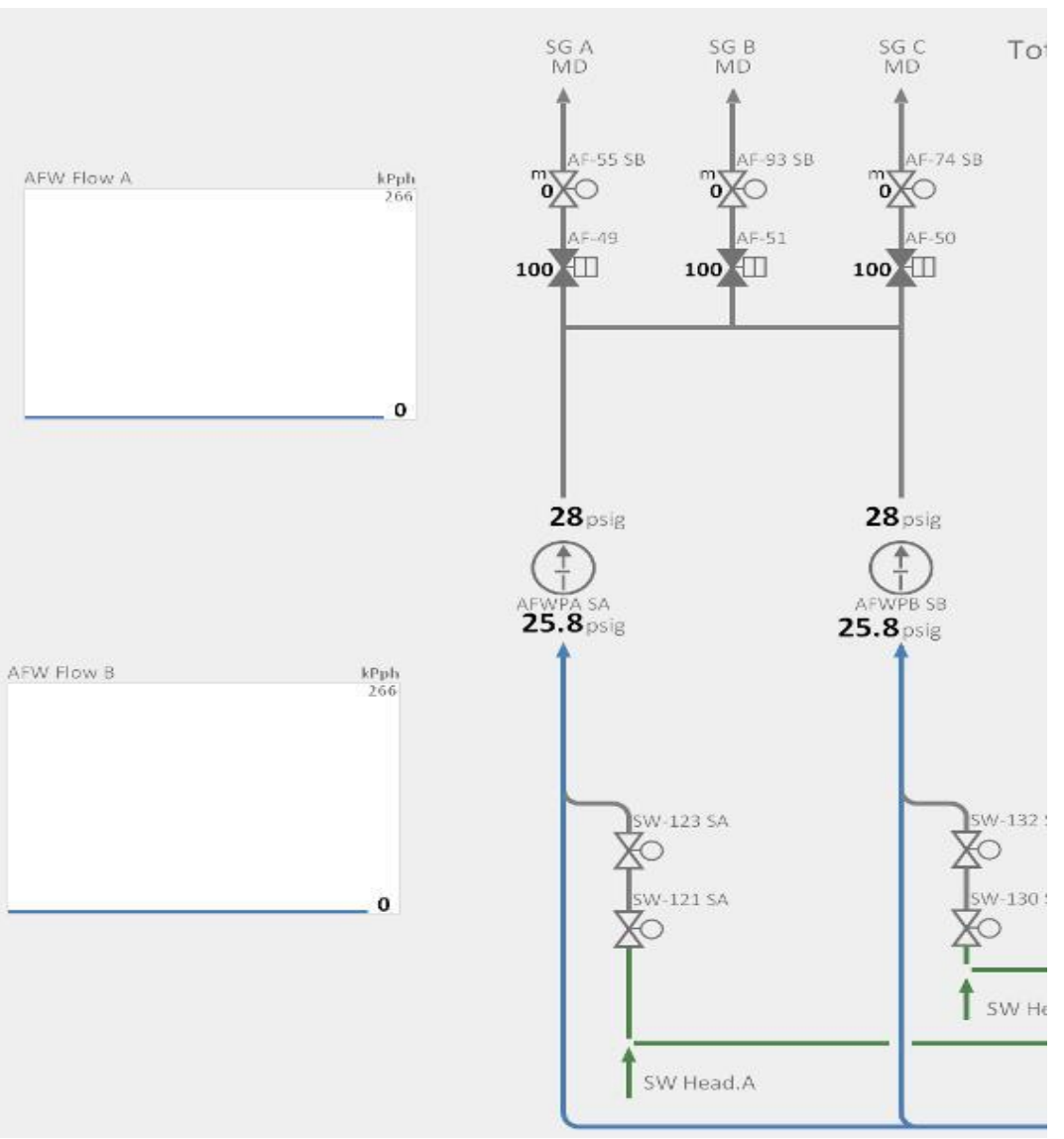

Figure 24. No Flow from AFW. 


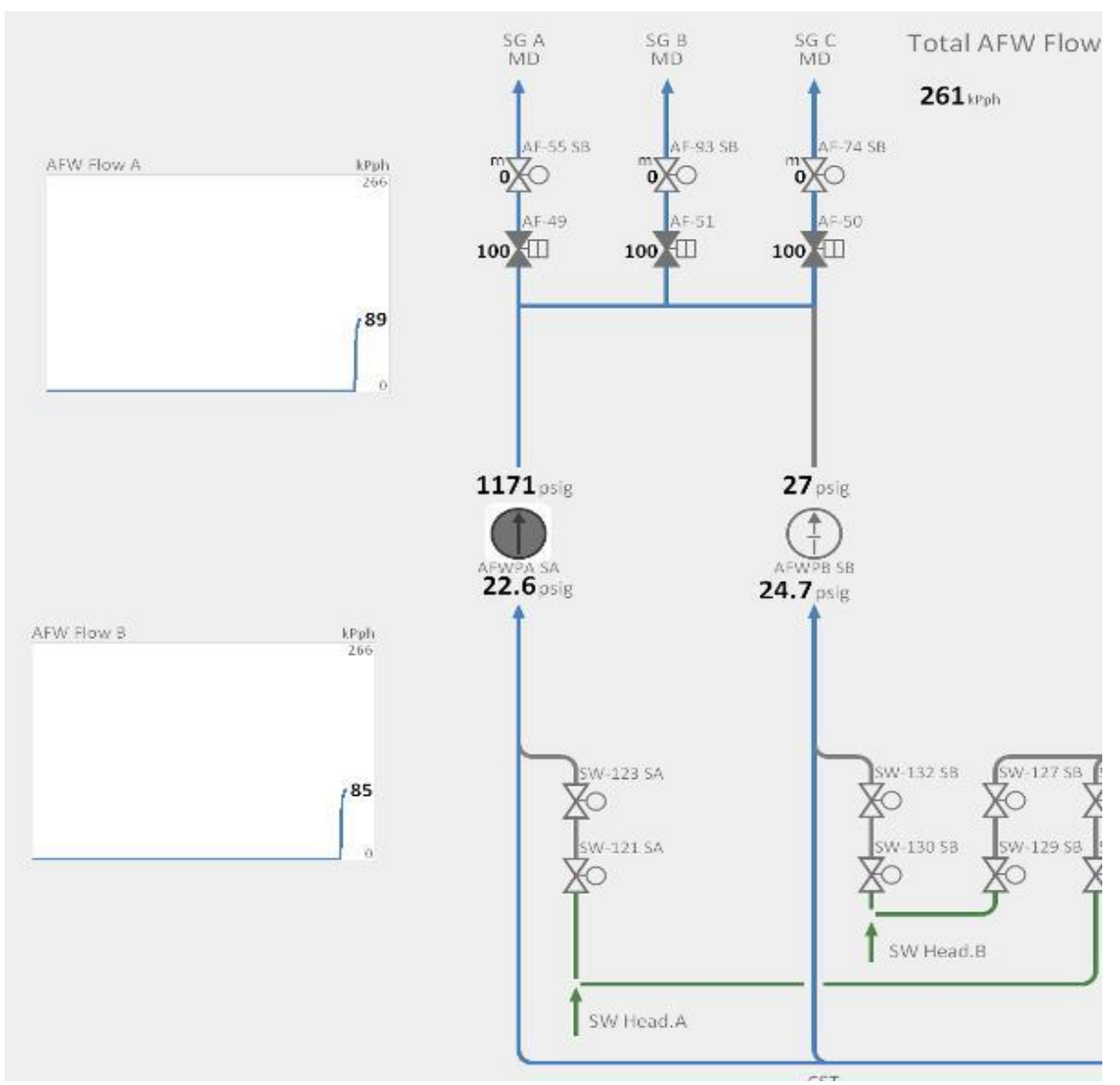

Figure 25. Flows from AFW.

\begin{tabular}{|c|c|c|c|}
\hline $\begin{array}{l}\text { SI reset } \\
\text { Train A }\end{array}$ & $\begin{array}{l}\text { SI reset } \\
\text { Train B }\end{array}$ & $\begin{array}{l}\text { Cnmt phase A } \\
\text { Train A }\end{array}$ & $\begin{array}{l}\text { Cnmt phase A } \\
\text { Train B }\end{array}$ \\
\hline (2) & ( & (2) & (2) \\
\hline Reset & Reset & Reset & Reset \\
\hline $\begin{array}{l}\text { Pressur. pres. } \\
\text { Train A }\end{array}$ & $\begin{array}{l}\text { Pressur. pres. } \\
\text { Train B }\end{array}$ & $\begin{array}{l}\text { Main st. pres. } \\
\text { Train A }\end{array}$ & $\begin{array}{l}\text { Main st. pres. } \\
\text { Train B }\end{array}$ \\
\hline OReset & Reset & Reset & Reset \\
\hline - Neutral & - Neutral & - Neutral & - Neutral \\
\hline Block & Block & Block & Block \\
\hline
\end{tabular}

Figure 26. Radio Buttons from RX CTRL. 


\section{SHARING EXPERIENCES WITH INL}

The IFE team conducted a visit to the INL offices and specifically the HSSL in July 2019. A new update of the IFE software found in the HSSL was conducted. The update consisted of the new configuration of the ACR that included three initial OWDs and the new navigation and control system. The three OWDs were tested in the HSSL and verified to be functional along with the flow/no flow process. A brief demonstration was conducted for some of the INL staff during the visit, and several topics regarding the OWDs were discussed.

A trip and new update are planned during the middle of October 2019. The new update will consist of the latest version of the OWDs and any new operating system updates. There will be a 2-day workshop for interested INL staff on the operation of the gPWR and the new OWDs. The workshop will consist of the basic operation of the reactor plant and then a more in depth look at the new OWDs and how they are used in the normal day-to-day operations and in the EOPs. Once the new update version of the OWDs are installed, INL staff members can start conducting additional human factors testing and provide additional feedback to IFE. This additional information and feedback will be reviewed, and any changes will be made prior to the next OWD update in the HSSL.

\section{CONCLUSIONS AND FURTHER WORK}

The new OWDs represent a step toward a new generation of display design, focusing on applying findings from Human Factors, industrial guidelines, and research into visual perception for computer displays. The completion of four new OWDs represents a new and interesting situation for the HSSL.

The HSSL now has the capability to switch between three different control platforms. The first being a legacy plant view on the glass-top bays that shows the plant as it was originally built and providing a simulation of analogue controls. The second simulator setup would be the current ACR with a mouse and display driven plant with an analogue look, using the original plant design as a templet for switches and meter indications. The third and final configuration will be a fully operational enhanced digital look and control using the OWDs as the controlling/operating system.

These three operating platforms will provide the possibility for INL to conduct further work on in-depth research on the effects of operations using different operating platforms. Based on this, INL and IFE can continue future work to improve the HSIs as well as collaboration on future experiments in the HSSL.

\section{REFERENCES}

ANSI/HFES 200 (2008) Human Factors Engineering of Software User Interfaces, Approved American National Standard, Eds.: Vanderheiden G., Bangor A., Gardner-Bonneau D., Williams J., publ. by Human Factors and Ergonomics Society, Santa Monica, USA.

ASM Consortium Guidelines, Second Edition (2013). Effective Console Operator HMI Design, Honeywell International Inc., Prep. By: ASM Joint R\&D Consortium, Bullemer P, Reising D. V., Publ. by ASM Consortium, USA.

Braseth A.O (2015). Information-Rich Design: A Concept for Large-Screen Display Graphics, Design principles and graphic elements for real-world complex processes, dr.philos thesis at NTNU, dep. Product Design.

Bullemer P., Reising D.V., Laberge J. (2011). Why Gray Backgrounds for DCS Operating Displays? The human Factors Rationale for an ASM Consortium Recommended Practice, ASM sponsored paper, accessed at http://www.asmconsortium.net/29. May 2012.

Endsley M. R. (2013), Situation Awareness, In Lee J. D. and Kirlik A. (Eds.), The Oxford Handbook of Cognitive Engineering, pp. 89, 99, Oxford University Press. 
Healey C.G, Enns J.T. (2012). Attention and Visual Memory in Visualization and Computer Graphics, IEEE Trans. On Visualization and Computer Graphics, Vol. 18, No. 7, pp. 1170-1188.

IEC 61772 (2009). International standard, Nuclear power plants - Control rooms - Application of visual display units (VDUs), Edition 2.0, International Electrotechnical Commission, Geneva, Switzerland.

ISO 11064-1 (2000). Ergonomic design of control centres - Part 1: Principles for the design of control centres, the International Organization for Standardization, Geneva, Switzerland.

ISO 11064-5 (2008). Ergonomic design of control centres - Part 5: Displays and controls, the International Organization for Standardization, Geneva, Switzerland.

Lakoff G., Johnson M. (1999). Philosophy in the Flesh, The Embodied Mind and Its Challenge to Western Thought, Basic Books, New York.

Lidwell W., Holden K., Butler J. (2010). Universal Principles of Design, 125 Ways to Enhance Usability, Influence Perception, Increase Appeal, Make Better Design Decisions, and Teach through Design, Rockport Publishers, Beverly Massachusetts.

NUREG-0700 (2002). Human-System Interface Design Review Guidelines, Rev. 2, Prep. By: O’Hara J.M., Brown W.S, Lewis P.M., Persensky J.J., U.S. Nuclear Regulatory Commission, Washington, USA.

Tharanathan A., Bullemer P., Laberge J., Reising D.V., Mclain R, (2012). Impact of Functional and Schematic Overview Displays on Console Operator's Situation Awareness, Journal of Cognitive Engineering and Decision Making, Vol. 6, No. 2.

Tufte E. (1990). Envisioning Information, Graphics Press, Cheshire Connecticut.

Tufte E. (2001). The Visual Display of Quantitative Information, second edition, Graphics Press, Cheshire Connecticut.

Ware C. (2008). Visual Thinking for Design, Elsevier, Morgan Kaufmann Publishers, USA. 


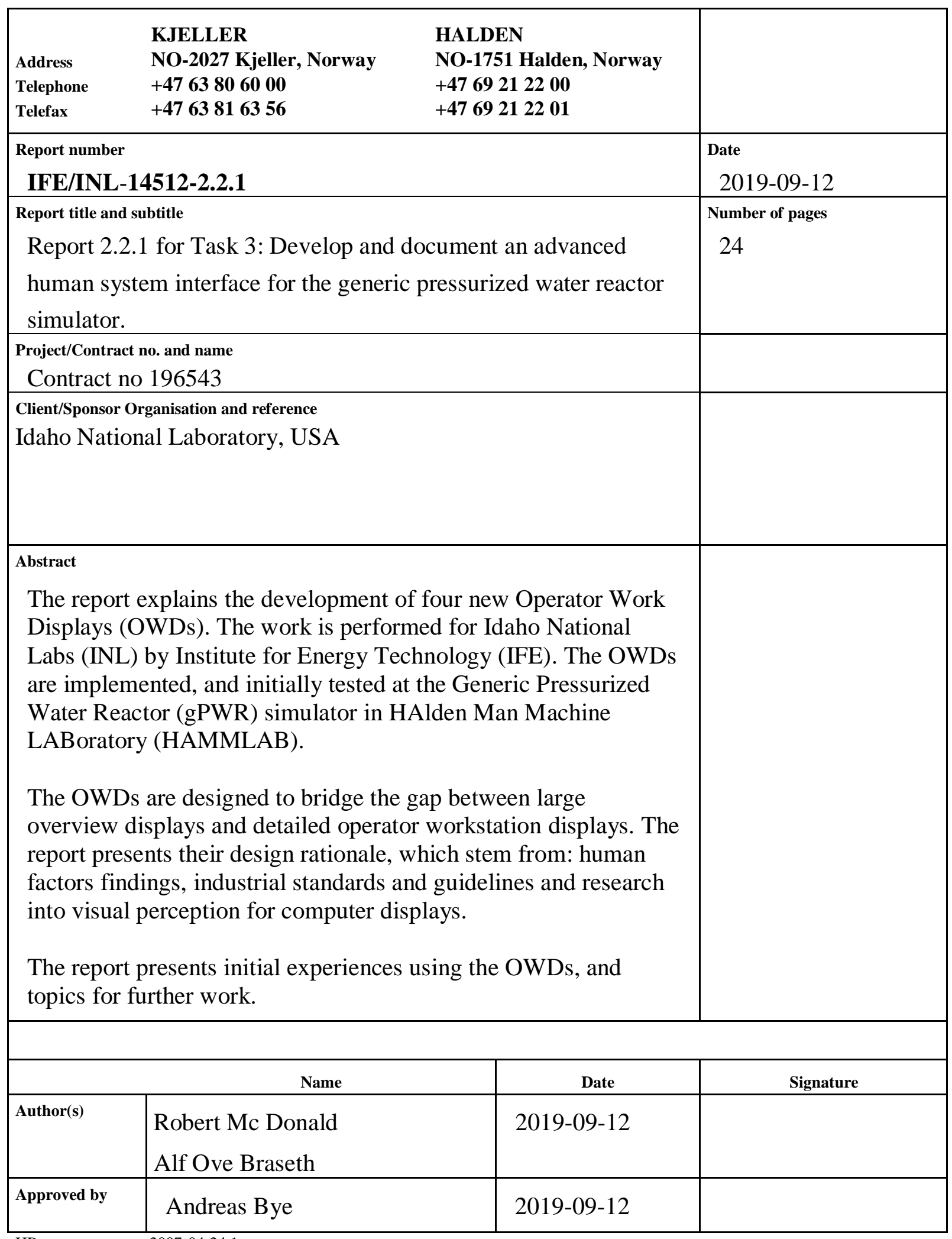

HR-e-rapport-e ver 2007-04-24.1 